\title{
Plasma exchange in the treatment of thyroid storm secondary to type II amiodarone-induced thyrotoxicosis
}

\author{
Ling Zhu', Sueziani Binte Zainudin', Manish Kaushik², Li Yan Khor ${ }^{3}$ and \\ Chiaw Ling Chng ${ }^{1}$ \\ Departments of ${ }^{1}$ Endocrinology, ${ }^{2}$ Renal Medicine, and ${ }^{3 P}$ athology, Singapore General Hospital, \\ Singapore
}

\section{Summary}

Type II amiodarone-induced thyrotoxicosis (AIT) is an uncommon cause of thyroid storm. Due to the rarity of the condition, little is known about the role of plasma exchange in the treatment of severe AIT. A 56-year-old male presented with thyroid storm 2 months following cessation of amiodarone. Despite conventional treatment, his condition deteriorated. He underwent two cycles of plasma exchange, which successfully controlled the severe hyperthyroidism. The thyroid hormone levels continued to fall up to $10 \mathrm{~h}$ following plasma exchange. He subsequently underwent emergency total thyroidectomy and the histology of thyroid gland confirmed type II AIT. Management of thyroid storm secondary to type II AIT can be challenging as patients may not respond to conventional treatments, and thyroid storm may be more harmful in AIT patients owing to the underlying cardiac disease. If used appropriately, plasma exchange can effectively reduce circulating hormones, to allow stabilisation of patients in preparation for emergency thyroidectomy.

\section{Learning points:}

- Type II AIT is an uncommon cause of thyroid storm and may not respond well to conventional thyroid storm treatment.

- Prompt diagnosis and therapy are important, as patients may deteriorate rapidly.

- Plasma exchange can be used as an effective bridging therapy to emergency thyroidectomy.

- This case shows that in type II AIT, each cycle of plasma exchange can potentially lower free triiodothyronine levels for $10 \mathrm{~h}$.

- Important factors to consider when planning plasma exchange as a treatment for thyroid storm include timing of each session, type of exchange fluid to be used and timing of surgery.

\section{Background}

Type II amiodarone-induced thyrotoxicosis (AIT) is a rare cause of thyroid storm and can be challenging to manage. Little is known about the use of plasma exchange in treatment of severe AIT. Current literature provides limited guidance on initiation of plasma exchange. Case reports outlining this treatment strategy, therefore, are of great value to physicians managing this unusual clinical entity.

\section{Case presentation}

A 56-year-old Chinese male presented with 2-week history of fever, cough and reduced effort tolerance. He had a history of atrial fibrillation and was treated with amiodarone for 
2 years. Following successful catheter ablation, amiodarone was discontinued 2 months before the current visit.

He was initially afebrile, stable and nontoxic at presentation but rapidly deteriorated 5 days after admission with high-grade fever of $40^{\circ} \mathrm{C}$, fast atrial fibrillation at a rate of 147 beats per minute and hypotension with blood pressure of $82 / 46 \mathrm{mmHg}$. Examination revealed a lethargic looking man with jaundice. He had no goitre or neck tenderness. There were no signs of thyroid eye disease or pretibial myxoedema.

\section{Investigation}

Laboratory investigations revealed severe hyperthyroidism, mild renal impairment, acute hepatitis as well as derangement in his coagulation profile (Table 1). Thyroid function was normal 4 and 8 months before this admission (Table 2).

Technetium-99m pertechnetate scan showed diffusely reduced tracer uptake throughout both thyroid lobes. Thyroid-stimulating hormone (TSH) receptor antibody was negative. Chest radiograph and echocardiography were unremarkable.

Thermodysregulation as well as cardiac and gastrointestinal manifestations of his thyrotoxicosis contributed to a high Burch-Wartofsky score of 80 (1). A diagnosis of thyroid storm secondary to type II AIT was made, based on the clinical findings (absent thyroid bruit and thyroid eye disease) and results of the thyroid uptake scan and TSH receptor antibody titre.

Table 1 Summary of laboratory results on admission.

\begin{tabular}{l}
\hline Laboratory test \\
\hline Biochemistry \\
Sodium \\
Potassium \\
Urea \\
Creatinine \\
Albumin \\
Bilirubin \\
Alkaline phosphatase (ALP) \\
Alanine transaminase (ALT) \\
Aspartate transaminase (AST) \\
Haematology \\
APTT \\
PT \\
Haemoglobin \\
WBC count \\
Platelet count
\end{tabular}

\begin{tabular}{|c|c|}
\hline Values & Reference range \\
\hline $135 \mathrm{~L}$ & $136-146 \mathrm{mmol} / \mathrm{L}$ \\
\hline 4.5 & $3.6-5.0 \mathrm{mmol} / \mathrm{L}$ \\
\hline $8.4 \mathrm{H}$ & $2.7-6.9 \mathrm{mmol} / \mathrm{L}$ \\
\hline $106 \mathrm{H}$ & 54-101 $\mu \mathrm{mol} / \mathrm{L}$ \\
\hline $38 \mathrm{~L}$ & $40-51 \mathrm{~g} / \mathrm{L}$ \\
\hline $58 \mathrm{H}$ & $7-32 \mu \mathrm{mol} / \mathrm{L}$ \\
\hline $111 \mathrm{H}$ & 39-99 U/L \\
\hline $615 \mathrm{H}$ & $6-66 \mathrm{U} / \mathrm{L}$ \\
\hline $962 \mathrm{H}$ & $12-42 \mathrm{U} / \mathrm{L}$ \\
\hline $34.5 \mathrm{H}$ & $25.7-32.9 \mathrm{~s}$ \\
\hline $12.8 \mathrm{H}$ & $9.9-11.4 \mathrm{~s}$ \\
\hline $12.9 \mathrm{~L}$ & $14.0-18.0 \mathrm{~g} / \mathrm{dL}$ \\
\hline 8.07 & $4.0-10 \times 109 / \mathrm{L}$ \\
\hline 205 & $140-440 \times 10^{9} / \mathrm{L}$ \\
\hline
\end{tabular}

Abnormal results are in bold. $\mathrm{H}$, above upper range of normal; $\mathrm{L}$, below lower range of normal; APTT, activated partial thromboplastin time; PT, prothrombin time.
Table 2 Thyroid function test results before and at presentation.

\begin{tabular}{|c|c|c|c|c|}
\hline $\begin{array}{l}\text { Thyroid } \\
\text { function }\end{array}$ & $\begin{array}{c}\text { Eight } \\
\text { months } \\
\text { ago }\end{array}$ & $\begin{array}{c}\text { Four } \\
\text { months } \\
\text { ago }\end{array}$ & At presentation & $\begin{array}{c}\text { Reference } \\
\text { range }\end{array}$ \\
\hline $\mathrm{FT}_{3}$ & - & - & 16.9 & $3.2-5.3 \mathrm{pmol} / \mathrm{L}$ \\
\hline $\mathrm{FT}_{4}$ & 13.9 & 14.7 & 64.0 & 8.8-14.4 pmol/L \\
\hline TSH & 1.81 & 1.65 & $<0.015$ & $0.65-3.70 \mathrm{mU} / \mathrm{L}$ \\
\hline
\end{tabular}

Deranged thyroid function at presentation, compared to results from routine tests 4 and 8 months prior to presentation.

\section{Treatment}

He was initially treated with oral propranolol $20 \mathrm{mg}$ every $8 \mathrm{~h}$, intravenous hydrocortisone $100 \mathrm{mg}$ every $6 \mathrm{~h}$, intravenous digoxin $500 \mu \mathrm{g}$ once, oral propylthiouracil $400 \mathrm{mg}$ once, Lugol's iodine $10 \mathrm{~mL}$ once and intravenous piperacillin/tazobactam $4.5 \mathrm{~g}$ once.

Propylthiouracil and Lugol's iodine solution were stopped the following day as they were of no therapeutic benefit in type II AIT. He was continued on intravenous steroids. Cholestyramine was initiated as an adjunctive therapy. In addition, his tachycardia was refractory to escalated doses of propranolol. Intravenous digoxin also failed to control his heart rate. Intravenous esmolol infusion was initiated and titrated up to $200 \mu \mathrm{g} / \mathrm{kg} / \mathrm{min}$, without achieving satisfactory rate control.

At this point, it was clear that the patient had fulminant thyrotoxicosis that was not responding to conventional medical treatment, and therapeutic options were limited by the severe derangement of his liver function. Hence, a decision was made to initiate early plasma exchange as a bridging therapy to emergency thyroidectomy.

Plasma exchange, with no anticoagulation, was performed the next day with right femoral vein double lumen dialysis catheter as angio-access. Plasma was separated by the membrane separation technique, using a PlasmaFlux P2 Dry filter mounted on Fresenius 4008S ARrT Plus platform (Fresenius Medical Care, Bad Homburg, Germany). Fresh frozen plasma (FFP), $3 \mathrm{~L}$, was used as exchange fluid. Heart rate improved from 126 beats per minute at the initiation time to 107 beats per minute on completion of the first cycle of plasma exchange. Systolic blood pressure was maintained between 133 and $158 \mathrm{mmHg}$. Free triiodothyronine $\left(\mathrm{FT}_{3}\right)$ and free thyroxine $\left(\mathrm{FT}_{4}\right)$ levels improved markedly following the first exchange (Table 3). These values were carefully trended every $4-6 \mathrm{~h}$, so that any rise of circulating thyroxine levels could be detected early (Fig. 1). 
Table 3 Serial $\mathrm{FT}_{3}$ and $\mathrm{FT}_{4}$ measures following two cycles of plasma exchange.

\begin{tabular}{|c|c|c|c|}
\hline $\begin{array}{l}\text { Time } \\
\text { (h) }\end{array}$ & $\begin{array}{l}\text { Hours from TPE } \\
\quad(\# 1 \text { and } \# 2)\end{array}$ & $\begin{array}{c}\mathbf{F T}_{\mathbf{3}} \\
(\mathrm{pmol} / \mathrm{L})\end{array}$ & $\begin{array}{c}\mathbf{F T}_{4} \\
(\mathrm{pmol} / \mathrm{L})\end{array}$ \\
\hline 19:30 & -3 & 10.2 & 76.6 \\
\hline 02:16 & 0 & 7.8 & 68.1 \\
\hline 06:05 & +4 & 6.8 & 61.7 \\
\hline $12: 17$ & +10 & 5.7 & 68.6 \\
\hline $21: 20$ & 0 & 5.9 & 55.1 \\
\hline $00: 23$ & +3 & 5.3 & 53.9 \\
\hline 04:14 & +7 & 4.7 & 51.3 \\
\hline \multicolumn{4}{|c|}{ Total thyroidectomy: $07: 50 \mathrm{~h}$ day 4 to $09: 15 \mathrm{~h}$ day } \\
\hline
\end{tabular}

TPE, therapeutic plasma exchange; \#1, first cycle: $22: 15 \mathrm{~h}$ day 2 to $01: 40 \mathrm{~h}$ day 3; \#2, second cycle: 17:10h day 3 to $21: 05$ day 3; day 1 , day on which thyroid storm was diagnosed.

Liver function had improved significantly (alanine transaminase $216 \mathrm{U} / \mathrm{L}$ and aspartate transaminase 297 U/L) by the second day of plasma exchange. He then underwent a second cycle, with $2.5 \mathrm{~L}$ of FFP and $0.5 \mathrm{~L}$ of $5 \%$ human albumin solution as exchange fluid. This successfully brought down his $\mathrm{FT}_{3}$ level to the normal range. Other biochemical and haematological markers that were closely monitored included serum calcium (risk of citrate-induced hypocalcaemia) and coagulation profile (possible removal of clotting factors during plasma exchange).

He underwent successful total thyroidectomy 4 days after initial diagnosis of thyroid storm.

Histopathology report subsequently supported the diagnosis of type II AIT. The thyroid specimen weighed $33 \mathrm{~g}$, with a tan-coloured, rubbery appearance on cross sections. No gross lesions were seen. Microscopically, there

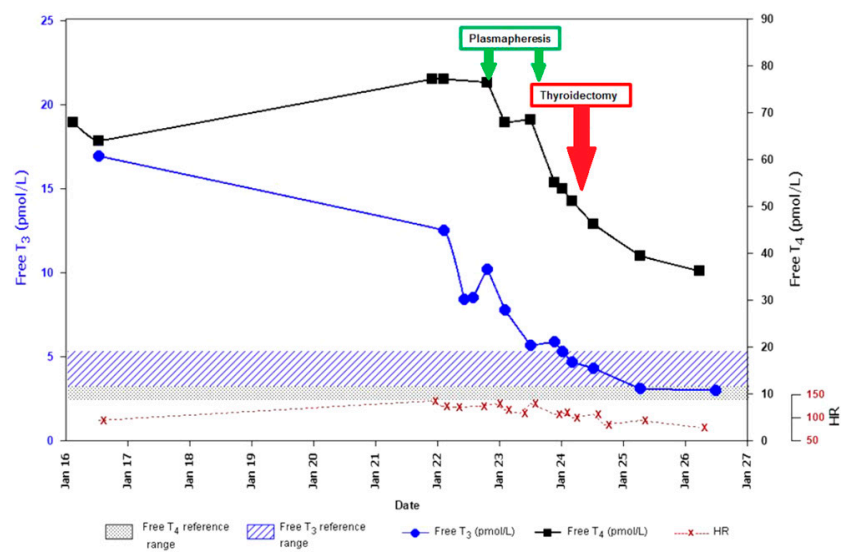

Figure 1

Trend of $\mathrm{FT}_{4}, \mathrm{FT}_{3}$, and heart rate over time. Each cycle of plasma exchange is annotated with a green arrow. Thyroidectomy was annotated with a red arrow. HR, heart rate (beats/minute).
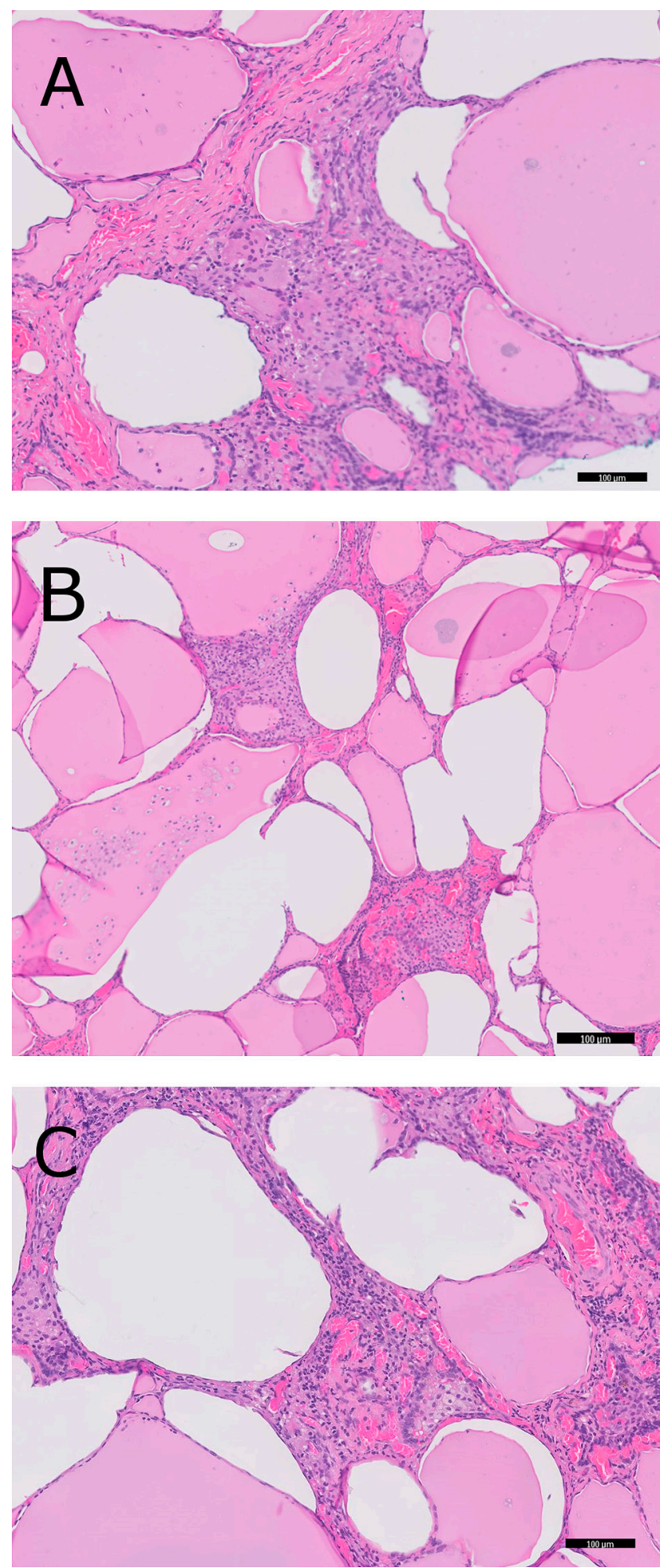

Figure 2

Microscopic appearance of the thyroid gland. Images are taken at $100 x$ magnification. (A) Follicles with packed stromal tissue containing multinucleated giant cells. (B) Follicles filled with desquamated epithelial cells. (C) Clusters of foamy histiocytes. 
was a predominance of colloid containing thyroid follicles. Several features compatible with type II AIT were seen, including foamy histiocytes, vacuolated desquamated epithelial cells and multinucleated giant cells (Fig. 2).

\section{Outcome and follow-up}

He made steady progress and was discharged 7 days following thyroidectomy. Thyroxine replacement was initiated 9 days later. Twelve months after discharge, his thyroid function was stable on thyroxine replacement.

\section{Discussion}

Type II AIT is a rare cause of thyroid storm. A recent case series from our institution described Graves' disease as the predominant aetiology of thyroid storm (2). The main challenges in the management of our patient were his rapid clinical deterioration from thyroid storm and gaps in the current literature to guide us on the timing and frequency of plasma exchange.

Plasma exchange as a treatment modality in management of thyroid storm, though rare, is not new. By exchanging the patient's plasma with the donor's plasma and/or human albumin solution, it is hoped that a lower level of circulating thyroid hormone can be achieved.

In 1970, Ashkar and co-workers first described the use of blood exchange and plasmapheresis in treatment of "thyrotoxic crisis" (3). Forty-three years later, the American Society for Apheresis (ASFA) 2013 guidelines on the use of therapeutic apheresis listed thyroid storm as a category III indication (optimum role of apheresis therapy is not established, decision making should be individualised) for therapeutic apheresis (4). The level of evidence is low due to lack of robust data in this area, but this is unlikely going to change in the near future due to the sheer rarity of the condition.

In the absence of clear guidelines and recommendations on the use of plasma exchange in treatment of patients with thyroid storm or severe thyrotoxicosis, the decision to utilise this modality of therapy has to be made by the treating physician.

Our patient with severe AIT was particularly difficult to treat. The long half-life and large volume of distribution of amiodarone contribute to the sustained effect of amiodarone on thyroid function (5). As the pathogenesis of AIT can be heterogeneous, response to various components of conventional thyroid storm treatment is also limited. Type II AIT does not respond to anti-thyroid drugs. Pre-existing iodine saturation in the thyroid gland in such patients means that further iodine uptake will be minimal, hence the likely futility of iodine solution. Patients with severe AIT and thyroid storm can be potentially good candidates for plasma exchange. Multiple mechanisms of action have been proposed, such as removal of free and protein-bound hormones, iodine, inflammatory cytokines, amiodarone and autoantibodies (4).

When using plasma exchange as a bridging therapy to definitive treatment, that is, total thyroidectomy, a few factors pertaining to the technicalities have to be considered, namely, the timing of initiation of plasma exchange, the type of replacement fluid used and the number of exchanges needed before surgery.

\section{Timing of initiation of plasma exchange}

Our patient underwent plasma exchange on the day after diagnosis of thyroid storm. Most case reports recommend a trial of conventional therapy before consideration of plasma exchange (4). The reported intervals between the diagnosis of thyroid storm and the initiation of plasma exchange vary greatly. As each patient's clinical response and speed of deterioration are different, decision on the timing of plasma exchange and surgery should be made on an individual basis. As the window of opportunity to intervene is narrow, patients with thyroid storm secondary to AIT and unstable cardiac diseases should be considered for plasma exchange and thyroidectomy without delay.

\section{Type of replacement fluid used}

The ASFA guidelines on the use of therapeutic apheresis in clinical practice highlighted the advantages of using plasma as a replacement fluid, due to its ability to increase the concentration of thyroglobulin to bind free thyroid hormone (4). Other advantages of using FFP include the presence of clotting factors and immunoglobulins. The laboratory tests of our patient revealed raised transaminases and prolonged prothrombin time, indicating a degree of hepatic impairment, and hence an impaired hepatic synthetic function. This limits the regeneration of clotting factors and immunoglobulins. If such proteins are removed during plasma exchange and not replaced accordingly, coagulopathy and immunocompromised state may ensue. Risks associated with use of FFP include anaphylactoid reactions, viral transmissions and citrate toxicity. FFP contains $14 \%$ citrate by volume, and chelation of calcium by citrate may lead to hypocalcaemia (6). 


\section{Number of exchanges needed before surgery}

The aim of plasma exchange for our patient was to reduce the level of circulating thyroid hormone such that he would be fit to undergo emergency thyroidectomy under general anaesthesia. There is no consensus or guideline on the number of exchanges necessary. Muller and co-workers reviewed the literature and analysed cases of thyroid storm requiring plasma exchange (7). There is great heterogeneity in the indications for plasma exchange, as well as the definitions of clinical improvement and hence clinical endpoint. Nonetheless, the median number of exchanges required ranged from 1 to 6 . In case reports specific to AIT, patients generally underwent a sufficient number of exchanges to render their $\mathrm{FT}_{3}$ levels normal or near normal, before total thyroidectomy took place (8).

We observed in our patient that after the completion of each cycle of plasma exchange, both the serum $\mathrm{FT}_{3}$ and $\mathrm{FT}_{4}$ levels continued to decrease, for up to $7-10 \mathrm{~h}$. This can probably be explained by the availability of new thyroid hormone-binding sites offered by proteins in the FFP, allowing for a constant equilibration of the hormone between free and bound states.

\section{Conclusion}

Plasma exchange is not without its risks, and thus cannot be recommended as standard treatment for type II AIT. It should not be offered to patients with stable cardiac disease and delayed response to AIT therapy. Complications of plasma exchange include citrateinduced hypocalcaemia, coagulation abnormalities, infection, electrolyte abnormalities, and hypotension (6). When complications arise, plasma exchange may need to be terminated (9). In our patient, we monitored his serum calcium level closely following thyroidectomy, as postoperative hypoparathyroidism can further cause disturbance to calcium homeostasis. Coagulation profile was also checked to minimise the risk of bleeding in the peri-operative period.

This case highlights the important of prompt diagnosis of AIT and early initiation of treatment. When conventional treatments fail, however, plasma exchange may be useful as a bridging modality to definitive therapy in selected unstable patients with severe AIT and thyroid storm.
Declaration of interest

The authors declare that there is no conflict of interest that could be perceived as prejudicing the impartiality of the research reported.

\section{Funding}

This research did not receive any specific grant from any funding agency in the public, commercial, or not-for-profit sector.

\section{Patient consent}

Written informed consent has been obtained from the patient for publication of the submitted article and accompanying images.

Author contributions and acknowledgements

$L Z$ and S B Z were responsible for reviewing the literature, writing the manuscript and editing the final version. $\mathrm{M} \mathrm{K}$ was involved in planning of plasma exchange. LY K was involved in analysing the histology slides. C L C was involved in the overall supervision and final approval of the manuscript.

\section{References}

1 Nayak B \& Burman K 2006 Thyrotoxicosis and thyroid storm. Endocrinology Metabolism Clinics of North America 35 663-686. (doi:10.1016/j.ecl.2006.09.008)

2 Swee DS, Chng CL \& Lim A 2015 Clinical characteristics and outcome of thyroid storm: a case series and review of neuropsychiatric derangements in thyrotoxicosis. Endocrine Practice 21 182-189. (doi:10.4158/EP14023.OR)

3 Ashkar FS, Katims RB, Smoak WM \& Gilson AJ 1970 Thyroid storm treatment with blood exchange and plasmapheresis. JAMA 214 1275-1279. (doi:10.1001/jama.1970.03180070041007)

4 Schwartz J, Winters JL, Padmanabhan A, Balogun RA, Delaney M, Linenberger ML, Szczepiokowski ZM, Williams ME, Wu Y \& Shaz BH 2013 Guidelines on the use of therapeutic apheresis in clinical practice-evidence-based approach from the Writing Committee of the American Society for Apheresis: the sixth special issue. Journal of Clinical Aphereresis 28 145-284. (doi:10.1002/jca.21276)

5 Latini R, Tognoni G \& Kates RE 1984 Clinical pharmacokinetics of amiodarone. Clinical Pharmacokinetics 9 136-156. (doi:10.2165/00003088-198409020-00002)

6 Kaplan AA 2008 Therapeutic plasma exchange: core curriculum 2008. American Journal of Kidney Diseases 52 1180-1196. (doi:10.1053/ j.ajkd.2008.02.360)

7 Muller C, Perrin P, Faller B, Richter S \& Chantrel F 2011 Role of plasma exchange in the thyroid storm. Therapeutic Apheresis and Dialysis 15 522-531. (doi:10.1111/tap.2011.15.issue-6)

8 Babić BK, Ljutić D, Brnić D, Dodig J 2007 The role of plasmapheresis in the treatment of amiodarone-induced thyrotoxicosis. Dialysis \& Transplantation 36 227-229. (doi:10.1002/dat.20123)

9 Diamond TH, Rajagopal R, Ganda K, Manoharan A \& Luk A 2004 Plasmapheresis as a potential treatment option for amiodaroneinduced thyrotoxicosis. Internal Medicine Journal 34 369-370. (doi:10.1111/imj.2004.34.issue-6)

Received in final form 9 May 2016

Accepted 8 June 2016 